\title{
TEORÍA DE LOS JUEGOS: UNA VISIÓN PRÁCTICA, PROCEDIMENTAL Y NORMATIVA DEL PROCESO PENAL
}

\author{
Rafaela Cândida Tavares Costa* \\ Thainá Penha Pádua**
}

\begin{abstract}
Resumen: La teoría de los juegos o teoría de juegos es un área de la matemática aplicada que examina situaciones estratégicas, en donde los jugadores deben elegir sus subterfugios en la tentativa de ganar la partida, teniendo el mejor retorno posible. Inicialmente la teoría fue desarrollada como una herramienta de compresión sobre el comportamiento de la economía, sin embargo, actualmente es utilizada en diversas áreas, siendo el derecho una de ellas. Es sobre la teoría de juegos, aplicada al derecho procesal penal, que se basa la presente investigación, específicamente sobre el análisis de la visión práctica acerca de las reglas (normatividades) referentes al procedimiento, verificando
\end{abstract}

* Licenciada por la Fundación Universidad de Itaúna. Especialista en Derecho Registral y Notarial, Civil y Empresarial por la Facultad Damásio/Ibmec. Maestra y doctoranda sobre Protección de los Derechos Fundamentales por la Fundación Universidad de Itaúna. Abogada, técnica contable y profesora titular en la Fundación Educacional de Oliveira (FEOL). Divinopólis (Brasil). Correo-e: rafaelacandida@live.com.

** Licenciada por el Centro Universitário de Lavras. Especialista en Derecho Procesal por la Fundación Educacional de Oliveira (FEOL). Abogada y profesora titular en la Fundación Educacional de Oliveira, Divinopólis (Brasil). Correo-e: advocaciapadua@gmail.com. Fecha de recepción: 9 de mayo de 2020. Fecha de aceptación: 12 de enero de 2021. Para citar el artículo: RafaEla CÂNDIDA TAVAres Costa, ThaInÁ PEnHA PÁduA. "Teoría de los juegos: una visión práctica, procedimental y normativa del proceso penal”, Revista Derecho Penal y Criminología , vol. 41, n. ${ }^{\circ} 110$, enero-junio de 2020, Bogotá, Universidad Externado de Colombia, pp. 161-175. DOI: https://doi.org/10.18601/ 01210483.v41n110.07. 
las exigencias del juego procesal penal. Se adoptó, por lo tanto, como procedimiento el análisis documental y revisión bibliográfica; y como método de inferencia, el deductivo. La presente investigación utiliza como marco teórico el libro La teoría de los juegos aplicada al proceso penal de Alexandre Morais da Rosa. En relación con los estudios, se percata la existencia de una diferencia entre el proceso a nivel normativo y práctico, no siendo esta una justificativa para que las reglas no sean obedecidas.

Palabras clave: teoría de los juegos; derecho procesal penal; visión práctica; normatividad; procedimiento.

\title{
GAMES THEORY: A PRACTICAL, PROCEDURAL AND REGULATORY VISION OF THE CRIMINAL PROCESS
}

\begin{abstract}
Game theory or game theory is a branch of applied mathematics that deals with strategic situations, where the players must choose their subterfuge in an attempt to win the game, having the best possible return. Initially the theory that had been developed as a tool for behavioral understanding of economics, today it is used in several areas, being Law, one of them. It is about game theory, applied to criminal procedural law, that this research deals, specifically about the analysis of the practical view about the rules (normativity) referring to the procedure, verifying the requirements of the criminal procedural game. For this purpose, document analysis and bibliographic review were adopted as a procedure; and as a method of inference, the deductive. The research adopts as a theoretical framework the book The Game Theory Applied to the Criminal Procedure by Alexandre Morais da Rosa. Regarding the results, there was a difference between the process at a normative and practical level, which is not a justification for not following the rules.
\end{abstract}

Keywords: game theory; criminal procedural law; practical vision; normativity; procedure.

\section{INTRODUCCIÓN}

La amplia defensa, en conjunto con la contradictoria y simétrica paridad de armas, es uno de los principios que orientan la aplicación de la ley penal. Dicho fundamento o pilar se encuentra previsto en el artículo $5 .^{\circ} \mathrm{LV}$ de la Constitución de la República Federativa de Brasil de 1988. De acuerdo con este artículo, el reo de eventual proceso penal posee plena capacidad probatoria en contraste con las de la acusación, con ciencia previa e integral del contenido de ésta, compareciendo y participando activamente de los actos procesales, representado por el defensor técnico. Por lo tanto, el proceso es construido en diversas fases hasta que llegue a su resultado final. 
La forma más actual y dinámica de actuar en el proceso y comprenderlo es realizar su interpretación como si éste fuera un juego, en el que el desarrollo procesal consiste en tácticas y jugadas estratégicas entre las partes involucradas, con el objetivo de obtener el mejor resultado jurídico. La teoría de juegos o teoría de los juegos se refiere a un área de la matemática aplicada que examina situaciones estratégicas, en donde los actores del juego (jugadores), a su vez llamados 'autor', 'reo', entre otros, deben elegir sus subterfugios en la tentativa de ganar el juego, teniendo el mejor retorno posible. Inicialmente la teoría fue desarrollada como una herramienta de compresión sobre el comportamiento de la economía, sin embargo, actualmente es utilizada en diversas áreas, siendo el derecho una de ellas. Es sobre la teoría de juegos, aplicada al derecho procesal penal, que se basa la presente investigación, específicamente sobre el análisis de la visión práctica acerca de las reglas (normatividades) referentes al procedimiento, verificando las exigencias del juego procesal penal.

La presentación de la investigación se inicia con la problemática que la rodea, que es el choque entre la normativa procedimental penal y la realidad procesal. Los operadores del derecho, una vez $\mathrm{u}$ otra, quieren huir de las reglas sobre las normativas procesales mencionadas en la hora de la práctica, pero esto no es necesariamente un problema. El problema es la forma como esta pretensión se materializa. Algunos jugadores del juego procesal hacen uso de astucia y de lenguajes disimulados. La teoría de juegos aparece como un esfuerzo, cuando es aplicada al derecho, para reclamar la atención de los jugadores hacia la realidad para impedir una manipulación teórica, ideológica y hermenéutica. Dependiendo de la explicación de la teoría matemática en cuestión, cuando se aplica al procedimiento penal se puede inferir que a los jugadores se les permitiría cualquier maniobra, ya que es una competencia, con el objetivo claro y específico de la victoria, como si un gol con la mano, en el fútbol, fuera válido.

De lo anterior, con respecto al problema que permea esta investigación, este trabajo se justifica para que el tema actual se agote como se merece. Además, estas confusiones entre las normas procesales penales y la realidad procesal justifican este estudio, sirviendo a la investigación para resolver cualquier duda con respecto a la aplicación de la teoría de juegos en el proceso penal.

La hipótesis del estudio es la distinción entre el proceso a nivel normativo y práctico, lo cual no es una justificación para no seguir los preceptos, dejando en claro que en ambos planes las reglas deben ser claras, predeterminadas, objetivas y específicas, siempre honrando el fair play.

El trabajo es el resultado de una investigación en la cual se adoptó el análisis documental, así como la revisión bibliográfica, con la consulta de artículos científicos y libros relacionados con el tema, siendo la principal fuente de consulta y marco teórico de esta investigación el libro La teoría de los juegos aplicada al proceso penal de Alexandre Morais da Rosa. 
Estructuralmente, el estudio se divide en dos secciones temáticas, además de esta introducción y conclusión. En la primera sección, titulada Visión procesal a través de la teoría de juegos, se estudiará la aplicación de esta teoría en el derecho procesal penal y sus consecuencias. A su vez, en la siguiente sección, Tácticas y estrategias para llevar a cabo el proceso, se analizarán algunas estrategias vinculadas a la teoría de juegos aplicada al derecho procesal penal para ejemplificar y profundizar el estudio presentado en la segunda sección.

Con respecto al punto de vista para abordar el problema, la investigación es de tipo cualitativo, la cual se preocupa por la profundización de la comprensión del objeto de estudio.

El objetivo general del estudio es analizar la teoría de juegos aplicada al proceso penal. A su vez, los objetivos específicos son estudiar la concatenación entre el plan práctico y teórico del proceso penal, mencionando a los jugadores y sus roles, abordando posibles problemas frente a las reglas a las que obedecen y explicar cómo deben construirse las estrategias en la práctica, para que la normatividad teórica no se vea perjudicada.

Por lo tanto, el estudio aborda los principios constitucionales brasileños, la protección legal de los derechos fundamentales, los procesos y procedimientos penales inquisitivos y acusatorios. Como está directamente relacionado con los dramas humanos, el proceso penal puede verse como un juego, de modo que las variables personales, los profesionales y las prácticas de los involucrados se tienen en cuenta para aminorar la situación del acusado.

\section{VISIÓN PROCESAL A TRAVÉS DE LA TEORÍA DE JUEGOS}

La idea de ver el procedimiento penal a través de la teoría de juegos surgió del texto celebrado por Piero Calamandrei ${ }^{1}$, y actualmente es una de las formas más estratégicas de analizar el procedimiento y los actores involucrados en él.

Alexandre Morais da Rosa refinó el tema del presente estudio en su trabajo La teoría de los juegos aplicada al proceso penal, marco teórico de esta investigación, así como en el libro Guía del proceso penal según la teoría de juegos. La teoría de juegos aplicada al derecho procesal penal se esfuerza por dar una visión más práctica, realista e incluso competitiva del proceso, con la "suposición de que el resultado procesal no depende exclusivamente del desempeño de uno de los jugadores, sino que resulta de la interacción de estrategias y tácticas utilizadas en el límite temporal del proceso"2.

1 Calamandrei, Piero. Revista de direito processual civil: O processo como jogo. Curitiba: Gênesis, 2002.

2 Rosa, Alexandre Morais da. Guia do Processo Penal conforme a Teoria dos Jogos. Rio de Janeiro: Lumen Juris, 2013. 
El reo, su defensor o defensores, el Ministerio Público, los jueces (árbitro) y la audiencia (aquí referidos a los medios de comunicación y otros espectadores) son personajes involucrados en el proceso penal. Como en un juego de fútbol (o en cualquier otro juego que prefiera el lector), en el que el factor humano es decisivo, así como la imprevisibilidad, el proceso penal tiene reglas y también requiere un cierto dinamismo.

Cabe señalar que, como en cualquier juego, el ser humano siempre necesita satisfacerse con la victoria cuando compite, haciendo con que el proceso penal se convierta, para los más punitivos, en un valor teórico, o, en palabras de Rosa ${ }^{3}$, en un "mito" a través del cual la decisión, el orden de las cosas y los personajes involucrados hipotéticamente regresarían al entorno colectivo/social, la paz.

Para Da Rosa ${ }^{4}$, el jugador es un subjectu, es decir, un sujeto procesal por debajo de las normas. La libertad de jugar no es amplia y sin restricciones, sino que posee límites preestablecidos a nivel teórico-normativo. El proceso, por lo tanto, solamente podría subsistir si se respetan las reglas y los principios que lo rodean y lo guían. Obviamente, siempre habrá espacios regulatorios relativamente abiertos, o lagunas, en los que los participantes del juego, si son creativos, encontrarán soluciones para ganar el partido. Por lo tanto, la legalidad debe observarse estrictamente, respetando el principio de la presunción de inocencia, consagrado en la carta constitucional brasileña de 1988, en el Pacto de San José de Costa Rica (Convención Americana sobre Derechos Humanos) (CIDH), en la Declaración de los Derechos del Hombre y del Ciudadano (USP), entre otras normativas relevantes en los ámbitos nacional e internacional.

El poder estatal punitivo y la intervención en la libertad individual de los ciudadanos deben ser legitimados y justificados a través de un procedimiento penal reipersecutorio justo y con reglas preestablecidas, vedada la sorpresa. La víctima sería, según Lopes Junior $^{5}$, el jugador hiposuficiente, recibiendo la tutela penal debido a este status.

En el proceso penal se produce una importante modificación: la persona más débil se convierte en el acusado que, en vista del poder del Estado para acusar, sufre la violencia institucionalizada del proceso y, más tarde, de la pena ${ }^{6}$.

El debido proceso legal, en su aspecto sustancial y como directriz para un procedimiento justo y limpio, se refiere al requisito de observar las reglas del juego, asignando significados auténticos dentro de una tradición en la que tanto los jugadores

3 Ibíd.

4 Rosa, Alexandre Morais da. Guia do Processo Penal conforme a Teoria dos Jogos. Florianópolis: Empório do Direito, 2017.

5 Lópes Júnior, Aury. Direito Processual Penal. São Paulo: Saraiva, 2016.

6 Ibíd., p. 27. 
como el árbitro están insertos. Cada táctica o estrategia debe analizar la estructura subyacente. Modernamente, el debido proceso legal sustancial se concibe como una garantía que establece una limitación legítima del poder estatal.

Es cierto que todo comenzará con la investigación policial, donde se recopilará información para iniciar el proceso penal. En otras palabras, los involucrados y los testigos serán escuchados, así como se realizará la diligencia debida, con el objetivo de formar una base sólida (causa justa, materialidad y autoría) para la inauguración del enjuiciamiento penal. Desde el punto de vista arcaico, una investigación policíaca no es imprescindible para el armazón de la evidencia procesal; sin embargo, desde el punto de vista moderno, en el que encaja la teoría de juegos, esa pieza inquisitiva desempeña un papel indispensable en las prácticas previas al juego, como lo es el registro de arresto flagrante y otros documentos previos al procedimiento.

El hecho es que una acción penal no puede admitirse como una aventura procesal, dado que la simple situación de responder a un proceso ya etiqueta al acusado, con efectos indelebles en su personalidad, en su imagen social, en su dignidad, incluso si el resultado del juego es una absolución. Hay un etiquetado real de los acusados en los procesos penales. El simple hecho de que este sea el papel de cierto actor en el juego procesal ya lo coloca en una posición desfavorable además de recibir el enjuiciamiento por parte de la sociedad; sociedad ésta que también trae reflejos en el resultado del juego.

El gran mérito de la teoría de juegos es mostrar cómo suceden las cosas si los jugadores son agentes racionales, incluso con la interferencia de las presiones y emociones irracionales que puedan surgir. El punto principal es la posibilidad de trazar expectativas de comportamiento con esta premisa de comprensión. Aunque cada decisión está sujeta a sus propias contingencias, el juego procesal penal tiene sus reglas (normatividad), a las cuales ni los jugadores ni el juez pueden timar, aunque lo hacen en ciertos momentos, dependiendo del desenredar procesal ${ }^{7}$.

El proceso no es únicamente una ciencia del derecho procesal, no es únicamente técnica de su aplicación práctica, es también leal observancia de las reglas del juego, es decir, fidelidad en los modelos no escritos de corrección profesional, que demarcan los confines entre la elegante y valiosa maestría del esgrimista astuto y los trucos torpes del tramposo ${ }^{8}$.

El juego por jugar es el juego democrático desde la perspectiva del fair play (juego democráticamente limpio), derivada de la batalla de habilidades interrumpidas en el

7 Calamandrei. Ob. cit.

8 Ibíd., p. 196. 
proceso, no está permitido jugar deshonestamente, incluso si la realidad es diferente, según Calamandrei ${ }^{9}$.

Es importante mencionar el "dilema del prisionero", una teoría desarrollada por Robert Axelrod ${ }^{10}$ en la cual dos sospechosos son arrestados por la policía, que no tiene pruebas suficientes para una futura condena. Se les ubica en habitaciones diferentes y se les ofrece un trato: si uno denuncia (traiciona al otro) y el otro lo niega, éste cumplirá una condena de diez años y el que denunció será liberado. Si ambos están en silencio, colaborando entre sí, la pena será de seis meses para cada uno. Si los dos denuncian, cada uno tendrá una pena de cinco años. La decisión se tomará sin ninguna comunicación entre ellos ${ }^{11}$.

Cada jugador, de forma independiente, quiere maximizar su propia ventaja sin tener en cuenta el resultado del otro jugador ${ }^{12}$. Delatar es una estrategia dominante, ya que presenta el mejor resultado (dejar libre), si el otro tampoco lo hace. Lo que estará en prueba es la confianza entre ellos. Cuando los jugadores aprenden a estimar la probabilidad de deserción de los demás, su propio comportamiento estará influenciado por sus expectativas (de este comportamiento externo). De ahí la importancia de la cooperación y del juego limpio.

Una vez realizado el análisis de la visión procesal utilizando la teoría de juegos como parámetro, ahora pasamos al análisis de tácticas y posibles estrategias para llevar a cabo el proceso.

\section{TÁCTICAS Y ESTRATEGIAS PARA LLEVAR A CABO EL PROCESO}

Para saber cómo jugar el juego procesal penal, es interesante, e incluso necesario, que los actores/jugadores tengan ciertos conocimientos previos. La reputación de sus oponentes es un ejemplo. Como en un partido de fútbol (aquí se seguirá con esta analogía, para fines didácticos), la anticipación de movimientos, ataques y contraataques siempre será una ganancia, es decir, la preparación y anticipación de comportamientos es un punto favorable para cualquier jugador. Tener conocimiento sobre los antecedentes académicos del magistrado, por ejemplo, puede marcar la diferencia

9 Ibíd.

10 Axelrod, Robert. A evolución de la cooperación: el dilema del prisionero y la teoría de juegos. Madrid: Alianza Editorial Sá, 2007.

11 Ibíd.

12 Rubinstein, Ariel, et al. Theory of games and economic behavior. Princeton: Princeton University Press, 2007. 
para prever sus posibles decisiones, incluso por el hecho de comprender la corriente doctrinal adoptada por él.

Otra estrategia se refiere al conocimiento de las predilecciones sociales, políticas y religiosas de los jurados ${ }^{13}$, durante el procedimiento del jurado, que también interferirán en sus decisiones, dado que ningún ser humano puede estar completamente exento de sus propios juicios. Cuando, por ejemplo, el padre de una víctima de violación mata al violador de su hija, al ir al juicio por jurado es interesante que la defensa actúe, para lograr la conformación de un cuerpo de miembros/consejo de veredicto que probablemente se inclinarán por la absolución de su defendido. Para esto, es necesario establecer cuáles jurados podrían simpatizar con el acusado, como hombres, que tienen hijas o hermanas, apelando a este sentimiento paternal y fraterno para influir en sus decisiones.

La táctica o estrategia obviamente depende del lugar que esté el jugador en el juego. Pero hay un dinamismo que no se puede presuponer en su totalidad, una vez que las informaciones son constantemente incompletas. No hay tácticas y estrategias ideales, pero un buen jugador sabe cómo usar todas las armas legales que tiene a su disposición. Por lo tanto, será necesario un análisis no estandarizado de los jugadores procesales, dada la volatilidad de las condiciones del juego ubicadas en el tiempo y en el espacio, conscientes de los factores humanos. Pensar en el proceso penal de acuerdo a la teoría de juegos es tener un auxilio decisivo para comprender su diseño.

El partido comienza con la definición de la imputación (acusación) y la tesis defensiva (defensa) a partir de las informaciones previas al juego (investigación policial, acta policial generada por el delito flagrante o documentos). Por lo tanto, la fiscalía elabora la acusación/denuncia, y después del citado acto que convierte al sospechoso (o indiciado cuando hay una investigación policial en curso o completa) en un acusado, y en consecuencia en un jugador, que presenta la defensa preliminar. Los límites del juego procesal permanecen, en principio, con una posibilidad excepcional de alteración, prevista en el Código Procesal Penal.

Una estrategia interesante es la inmunización de las tesis acusatorias o defensivas. Básicamente consiste en señalar las debilidades de su tesis, anticipar ataques y desmantelar argumentos. Por lo tanto, si la defensa lo usa, por ejemplo, dependerá de ésta anticipar los ataques de la fiscalía, refutando rotundamente las fortalezas y atacando las debilidades. Con esto, el juez o los jueces, desde el principio, verifican que la defensa ha examinado todas las facetas del caso, conociendo sus estrategias y blindando sus argumentos.

13 Art. 5..$^{\circ}$ XXXVIII, $d$. "La institución del jurado es reconocida como [...] competente para juzgar delitos intencionales contra la vida.” Brasil, Constitución de 1988 de la República Federativa de Brasil. Siendo estos delitos aquellos previstos en el Código Penal brasileño, en el capítulo I, título I, de la Parte Especial. Brasil, Código Penal, 1940. (Brasil, 1941) (Brasil, 1988). 
Como ejemplo de la mención de excepcionalidades en la alteración de los límites del juego previstos en el Código Procesal Penal ${ }^{14}$ y también de otra estrategia procesal, se presenta el desaforamiento ${ }^{15}$, es decir, el desplazamiento del juicio de un distrito a otro, en casos de interés público o cuando haya dudas sobre la imparcialidad del jurado o a respecto de la seguridad personal del acusado. Esta solicitud refleja una maniobra, dentro de los límites legales, para evitar que los actores externos interfieran en la disposición final construida por el Consejo de Sentencias.

Una vez que se fijan los límites legales del juego procesal, entonces es necesario verificar las posibles fortalezas y debilidades (déficit de información), analizando el perfil y el mapa mental de los jugadores y del acusado, como cuáles son las expectativas de comportamiento, la afiliación teórica, verificar algunas decisiones anteriores pronunciadas en situaciones similares, investigación de doctrina y jurisprudencia, factores de presión internos y externos (medios de comunicación y sociedad), anticipación de payoffs (recompensas) y posibles acciones (contexto macro y micro del escenario del juego real).

Para entender la propuesta, es necesario establecer los lugares del juego: (a) juez (juez, magistrados, ministros); (b) jugadores (fiscalía, asistente de fiscalía, defensor y acusado); (c) la estrategia de cada jugador (uso del resultado); (d) tácticas de los movimientos (movimientos de cada subjuego); y (e) los payoffs (ganancias o retornos) de cada jugador con la estrategia y las tácticas ${ }^{16}$.

Con toda esta articulación, es posible elaborar un modelo de representación del juego con la anticipación de los subjuegos, posibles tácticas, tiempo del juego y medidas de eficiencia, centrados en la recompensa de los jugadores, es decir, lo que pretenden obtener del proceso. También es necesario un análisis de la efectividad de las tácticas, ya que la estrategia será mejor delimitada, realineando los movimientos procesales en caso de que la acusación lo necesite.

Dentro de cada desarrollo procesal existen numerosas técnicas para ser utilizadas, o al menos consideradas. Por ejemplo, en una audiencia de instrucción y juicio las preguntas formuladas al acusado, a la víctima y a los testigos marcarán la diferencia.

14 Decreto-Lei n. ${ }^{\circ} 3.689$, del 3 de octubre de 1941. Código de Procedimiento Penal, disponible en [www.planalto.gov.br/ccivil_03/decreto-lei/del3689compilado.htm] (consulta: 24 de abril de 2020).

15 Art. 427. Si el interés del orden público lo exige o si hay dudas sobre la imparcialidad del jurado o la seguridad personal del acusado, el Tribunal, a solicitud del Ministerio Público, del asistente, del demandante o del acusado o mediante la representación del juez competente, puede determinar el desaforamiento del juicio a otro condado en la misma región, donde esas razones no existen, prefiriendo las más cercanas. Brasil, Código de Procedimiento Penal, 1941 (Brasil, 1941). 
Solo una pregunta errónea y parcial puede llevar al acusado a su ruina. Y es en este punto que el juez formará su convicción para declarar su sentencia.

En el procedimiento común ordinario y sumario, inicialmente se escuchará a los testigos enumerados por la acusación. Antes de la audiencia acusatoria del testimonio, nace el momento oportuno para que la defensa utilice la estrategia de desacreditación del testigo, siempre que presente cualquiera de los requisitos previstos en el artículo 214 del Código Procesal Penal ${ }^{17}$. La policía responsable del arresto y de la conducción del entonces acusado también participará, informando cómo se enteraron del hecho, de la impresión sobre la autoría y de la materialidad. Luego, se escuchará a los testigos enumerados por la defensa, oportunidad en la cual los relatos anteriores pueden ser contrarrestados. Es importante tener en cuenta que en muchos casos es válido utilizar el llamado "testigo de referencia", que puede informar que conoce al acusado y que es un trabajador y no se dedica a actividades delictivas. Esta es otra estrategia que podría beneficiar al acusado, influyendo en la dosimetría de la sentencia.

En la primera fase de la dosimetría, el magistrado analizará las circunstancias judiciales, incluida la conducta social, que es el papel del acusado en la comunidad, insertado en el contexto de la familia, del trabajo, de la escuela, del vecindario, etc., y también la personalidad del agente, que es el conjunto de caracteres exclusivos de una persona, parte heredada, parte adquirida. Es el análisis dirigido a detectar si la personalidad está orientada hacia el crimen. Por lo tanto, dicho testigo puede ser de gran utilidad.

En el escenario siguiente, se escuchará a los expertos, se harán confrontaciones y el reconocimiento de personas y cosas, si corresponde. Estos pasos deben tener una participación proactiva por parte de la defensa, con miras a garantizar el respeto de los principios constitucionales de defensa amplia, paridad de armas contradictoria y simétrica, así como las normas procesales de procedimiento.

Al final, el acusado será escuchado en su interrogatorio, solo si así lo desea, puesto que tiene derecho al silencio, y este acto es principalmente un medio de defensa, en una perspectiva a favor del acusado. El orden de los factores en el procedimiento también es decisivo para asegurar las garantías constitucionales y procesales penales. La razón para que el interrogatorio sea al final radica en el hecho de que el acusado, como está en posición pasiva, necesita saber todo lo que está sucediendo en el proceso y todo lo que dijeron los otros participantes de la audiencia, para entonces ejercer plenamente su defensa, guiado por la defensa técnica.

17 Art. 214. Antes de que comience el testimonio, las partes pueden contradecir al testigo o argumentar circunstancias o defectos que los hacen sospechosos de parcialidad o indignos de fe. El juez consignará el contradictorio o argumento y la respuesta del testigo, pero sólo excluirá al testigo o no le otorgará un compromiso en los casos previstos en los arts. 207 y 208. Brasil, Código de Procedimiento Penal, 1941. (Brasil, 1941). 
Vale la pena mencionar que en caso de que el acusado haga uso de su derecho constitucional al silencio, respaldado por el principio de nemo tenetur se detegere (nadie está obligado a presentar pruebas contra sí mismo), esto no puede ser utilizado por el magistrado en detrimento suyo. Sin embargo, en la práctica está claro que el interrogatorio es un momento crucial y el silencio puede ser arriesgado, en especial cuando el juez tiene una mentalidad esencialmente inquisitiva. Todo lo anterior debe ser analizado por la defensa, de modo que ésta maneje las mejores tácticas en el juego procesal, con el fin de obtener el resultado más favorable para el reo.

La estrategia que se utilizará en los medios de prueba también es decisiva. Se deben predecir los retornos, es decir, se deben analizar las consecuencias (resultados de las jugadas). Sin dudas, el jugador (sujeto procesal) debe dominar la teoría penal y procesal penal, tener experiencia, comprender el carácter competitivo del proceso y sus matices prácticos, sin dejar de lado sus fallas y deficiencias, siendo esta también una técnica de juego.

Como la carga de la prueba recae en el jugador-acusador (Ministerio Público en Acción Penal Pública Incondicionada), debe llevar las informaciones que pretende usar al registro, mientras que el jugador-defensor organizará estrategias y tácticas basadas en los movimientos de la acusación. Formando un gran juego de ajedrez, gana el que logra poner a su oponente en jaque mate o, cuando la comparación se hace con referencia a un partido de fútbol, el que logra eludir la defensa y marcar más goles.

Se trata de una dinámica con varios momentos fundamentales. El fiscal, en la mayoría de los casos, aspira a la condena, mientras que el acusado y su defensor, obviamente, buscan la absolución. Para ambos, la victoria, reflejada en una decisión favorable es sumamente anhelada.

Apoyado por el principio de presunción de inocencia, basado en el artículo 5 LVII de la Constitución de la República Federativa de Brasil ${ }^{18}$, y por todos aquellos textos legales anteriormente mencionados, el acusado ya inicia la marcha procesal siendo presumiblemente no culpable, o al menos, eso es lo que debería suceder. El defensor tiene el deber de asegurar y mantener esta condición asegurada hasta el tránsito en juzgado de la sentencia penal condenatoria o absolutoria en sentido lato. Cualquier movimiento que perjudique esto es causa de probable anulación, como existe aquí, un flagrante que afronta a las reglas del juego procedimental.

Deben evitarse las jugadas que conducen a la inevitable conclusión de la culpa al final del proceso, así como las decisiones que determinan la ejecución provisional de la

18 Constitución de 1988 de la República Federativa de Brasil, disponible en [http://www.planalto.gov. br/ccivil_03/constituicao/ConstituicaoCompilado.htm] (consulta: 20 de abril de 2020). 
sentencia. La libertad del acusado es la condición más importante para su defensor, principalmente debido al caótico sistema penitenciario, que no se analizará aquí.

El proceso no es lineal. La inestabilidad y la imprevisibilidad son parte de cada momento procesal, en el que los jugadores lucharán para revertirlo, en caso de que el acto realizado les haya sido perjudicial. Esta guerra procesal busca la confrontación y la victoria, incluso si para esto el ganador no ha respetado las reglas del juego.

El problema subjetivo de ganar un juego sin fair play es que el charlatán puede hacer que su reputación se rompa cuando se revelen sus prácticas. Este compromiso ético de los jugadores/jueces todavía se encuentra inmerso en factores antecedentes de adhesión individual, en los cuales las reglas procesales pueden ser manipuladas ${ }^{19}$.

Por tanto, se justifica la noción de doping (métodos específicos que buscan aumentar el rendimiento de un atleta durante una competencia), puesto que

El Estado no puede practicar ilegalidades, omitir informaciones desfavorables, utilizar métodos que no están autorizados por la ley, potencializar inescrupulosamente elementos probatorios, incluso si los agentes piensan que sea por buenas razones, aumentando la capacidad de obtener victorias procesales ${ }^{20}$.

La teoría de juegos puede auxiliar mucho a los operadores de la ley, especialmente a la defensa, que al iniciar el juego debe ser realista y reconocer sus limitaciones, preparándose con mapas mentales de tácticas que se traducen en estrategias. Se requiere la capacidad de anticipar las adversidades que puedan surgir, así como la rápida elaboración de planes alternativos.

Otro punto importante es saber cómo manejar los aspectos emocionales que van a permear determinado proceso, tanto para el acusado como para sus aliados. El juego limpio/fair play es tan necesario como la victoria, sobre todo porque el proceso puede no poseer memoria, pero sus jugadores sí. Un juego sucio puede resultar en venganza por los oponentes, en un próximo juego o, incluso, en un próximo movimiento.

La libertad, uno de los aspectos más viscerales del ser humano, es el objeto principal del juego procesal. El defensor debe estar preparado para un proceso penal cada vez más complejo, multidimensional, multifacético y lleno de ambigüedades e incertidumbres.

La persecución penal puede verse como un campeonato (idea de combate), con varios partidos de juego, también con negociaciones, en los que, según la teoría de

19 Da Rosa. Ob. cit., 2017, p. 358.

20 Ibíd., p. 62. 
juegos, se analizará no sólo el proceso de tomar decisiones interdependientes entre los sujetos-jugadores, sino también los escenarios de interés para optimizar las propias ganancias y recompensas más allá de los registros. Dicha perspectiva estimula las relaciones procesales y garantiza a los participantes mayores posibilidades de victoria.

\section{CONSIDERACIONES FINALES}

El proceso penal es un conjunto de normas y reglamentos que ordenan el enjuiciamiento penal en detrimento de un presunto autor de un delito cuando en contra de éste pesen indicios suficientes de autoría y exista, obviamente, la evidencia de un delito. Cuando un individuo es procesado penalmente, tenemos, por un lado, el Estado-Juez con el poder exclusivo de castigar, también denominado "poder reipersecutorio", y por otro lado, el acusado, amparado por su defensor, privado o público, que responderá al delito que se le fue imputado, dentro de los límites legales.

Es posible visualizar la marcha procesal como un juego, en el que hay sujetos procesales con diferentes objetivos. Cuando la teoría de juegos comienza a aplicarse en la esfera procesal penal, muchas cuestiones antes no percibidas son de esta manera tomadas en consideración, con el afán de aproximar la teoría normativa a una visión más práctica, centrada en la realidad de los hechos, de que se trata de una situación competitiva, en la cual cada sujeto procesal, ahora llamados "jugadores", cumple un papel determinante con objetivos diversos. Por esta razón, el resultado final del partido (iter procesal) depende de forma exclusiva del rendimiento de los jugadores. La combinación de situaciones, las interferencias externas de la opinión pública, construidas con gran participación de los medios de comunicación, sumadas a las estrategias y tácticas utilizadas en los límites temporales del proceso son las que influirán en la construcción de la disposición final.

Esta visión puede implicar una lectura incorrecta de la práctica procesal penal. Algunos aplicadores del derecho pueden tratar de evadir las reglas estipuladas en el plan normativo procesal en el momento de la verdad. De hecho, la teoría difiere de la praxis. El proceso penal real es más fluido y dinámico que las ideas legalmente previstas. Esta distinción no es un problema. El problema se refiere al distanciamiento capcioso, engañoso y disimulado llevado a cabo por jugadores deshonestos con la norma abstractamente prevista. De modo que algunos jugadores utilizan ardides y disimulos para lograr el éxito y tener una disposición favorable.

La teoría de juegos aplicada al proceso penal aparece como un esfuerzo para reclamar la atención de los jugadores a la realidad, pero también para evitar la manipulación teórica, ideológica y hermenéutica. A los jugadores no se les permite cualquier maniobra, el trámite de acuerdo con la teoría antes mencionada es una competencia, pero esta tiene límites y reglas claras y preestablecidas. No es permitido a los jugadores cualquier jugada con el objetivo de victoria, como que no se considera con fines de puntuación un gol con la mano en el fútbol. Aquí, aquella máxima maquiavélica 
de que los fines justifican los medios no se aplica. Todo esto, porque los sujetos procesales siempre están por debajo de las normas.

Pensar en el proceso penal a través de la teoría de juegos es tener un auxilio decisivo en la comprensión de su desenlace. Es importante resaltar que las tácticas y estrategias ideales no existen, pero un buen jugador debe saber cómo usar todas las armas legales a su disposición, poniendo énfasis en la palabra legales. El buen jugador es el que blinda su defensa o ataque a través de la estrategia de inmunización, que utiliza los recursos legales para influir en la disposición final, pero también es el que reconoce sus deficiencias, para que pueda perfeccionarse.

Mientras todo esté conforme a la legalidad y se respeten las divergencias entre la teoría y la práctica, no habrá ningún problema en la articulación de estrategias procedimentales distantes de las reglas penales previstas en abstracto.

Siempre que alguien esté en proceso de recibir una sanción penal por el Estado, su libertad está en riesgo. Una vez que la defensa tiene consciencia de las mejores estrategias y anticipa las consecuencias, más chance tiene el acusado de obtener un mejor resultado final, ya sea su absolución o su sentencia justa. Esto también aplica para la defensa, y para los jueces, por supuesto.

El estudio de la teoría de juegos por parte de los operadores del derecho, especialmente en el ámbito criminal, es de gran valía para permitir a aquellos involucrados mejores posibilidades de recompensas y victorias y para que se perfeccione la aplicación del derecho, retomando la atención de la acusación, defensa y juez (jueces) a la realidad, impidiendo la manipulación teórica, ideológica y hermenéutica de las normas procesales penales.

\section{REFERENCIAS}

Axelrod, Robert. A evolución de la cooperación: el dilema del prisionero y la teoría de juegos. Madrid: Alianza Editorial Sá, 2007.

Calamandrei, Piero. Revista de direito processual civil: O processo como jogo. $\mathrm{Cu}-$ ritiba: Gênesis, 2002.

CIDH. Convenção Americana sobre Direitos Humanos, disponible en [https://www. cidh.oas.org/basicos/portugues/c.convencao_americana.htm] (consulta: 24 de abril de 2020).

Constitución de 1988 de la República Federativa de Brasil, disponible en [https:// www.planalto.gov.br/ccivil_03/constituicao/ConstituicaoCompilado.htm] (consulta: 20 de abril de 2020). 
Decreto-Lei n..$^{\circ} 3.689$, del 3 de octubre de 1941. Código de Procedimiento Penal, disponible en [http://www.planalto.gov.br/ccivil_03/decreto-lei/del3689compilado. htm] (consulta: 24 de abril de 2020).

Lópes Júnior, Aury. Direito Processual Penal. São Paulo: Saraiva, 2016.

Rosa, Alexandre Morais da. Guia do Processo Penal conforme a Teoria dos Jogos. Rio de Janeiro: Lumen Juris, 2013.

Rosa, Alexandre Morais da. Guia do Processo Penal conforme a Teoria dos Jogos. Florianópolis: Empório do Direito, 2017.

Rubinstein, Ariel, et al. Theory of games and economic behavior. Princeton: Princeton University Press, 2007.

USP, Direitos Humanos. Declaração de direitos do homem e do cidadão, 1789, disponible en [http://www.direitoshumanos.usp.br/index.php/Documentos-anteriores$\% \mathrm{C} 3 \%$ A0-cria\% C3\% A7\%C3\%A3o-da-Sociedade-das-Na\%C3\% A7\%C3\%B5 es-at\%C3\%A9-1919/declaracao-de-direitos-do-homem-e-do-cidadao-1789.html] (consulta: 20 de abril de 2020). 